\title{
Knowledge sharing in a multicultural environment: challenges and opportunities
}

\author{
Luyanda Dube ${ }^{\prime}$ \\ Department of Information Science, University of South Africa \\ dubel@unisa.ac.za
}

Patrick Ngulube ${ }^{2}$

Department of Interdisciplinary Research of the College of Graduate Studies, University of South Africa

ngulup@unisa.ac.za

Received 22 November 2011

Accepted 2 July 2012

The article underscores the process of knowledge sharing in a multicultural organisational environment. Generally, multiculturalism emanates from being influenced by different contexts that provide the potential for human diversity. It results in disparate behavioural patterns and bodies of knowledge which lead to variance in terms of racial, sexual, age and cultural orientations. The process of sharing knowledge is complex and is susceptible to multicultural variances. Considering that knowledge sharing processes and probable multicultural influences are contextual, the purpose of the article is to establish the extent of knowledge flows in the Department of Information Science at the University of South Africa. In particular the article seeks to give an overall view on how knowledge is shared across intergenerational, cultural and interracial lines in the Department. The qualitative approach was considered appropriate for this study because it focuses on observing events from the perspectives of those who are involved and is aimed at understanding the attitude, behaviour and opinions of those individuals (Powell \& Connaway 2004). A basic interpretive qualitative research design was used for this study. Data was collected through interviews and document analysis. The data were inductively analysed and the findings are presented and discussed using references to the literature that informed the study.

Keywords: Cultural diversity, knowledge, knowledge management, knowledge sharing, South Africa

\section{Context and caveats}

There is an old adage that knowledge is power. However, a more recent strong conviction is that the value of knowledge increases when it is shared. Knowledge is considered to be the main driver of the economy in a knowledge economy landscape (Kamal, Manjit \& Gurvinder 2007). This is largely due to the undisputed fact that it is a valuable and strategic asset (Butler et al., 2004; Raja \& Raja 2008) that enables organisations to achieve a competitive advantage and resilience (Jain 2009; Mohsam \& Van Brakel 20I I). Griffiths (1998) avers that the evolution of knowledge management (KM) as one of the progressive organisational tools is an endorsement of the need to leverage knowledge as an important resource by ensuring that it is made accessible to the right people at the right time. Sharing knowledge which is one of the key components in the domain of knowledge management is about the systematic and deliberate endorsement of the movement of relevant information, ideas, suggestions and expertise generated by one self or acquired through routine activities, or borrowed from one's social network (Bartol \& Srivastava 2002).

The article reflects on knowledge sharing in a typical South African organisation mainly characterised by the prevalence of racial, cultural, nationality, ethnic and other differences. Table I shows that the profile of academics in the Department of Information Science is diverse in terms of race, culture, nationality and generation. This diversity and heterogeneity may pose a challenge when it comes to knowledge sharing. Culture and race may be inhibit the development of openness and trust amongst the staff members (Ford \& Chan 2003). A lack of trust may be inimical to knowledge sharing in an organisation (Ngulube 2005).

Various diversity studies have conclusively shown that organisations which make full use of their collective knowledge and expertise may be more efficient, effective, and creative (Cloete 2007; Du Toit \& Steyn 20II; Finestone \& Snyman 2005; Kruger \& Johnson 2009), whilst those that fail to effectively capitalise on diversity potential (Boone \& Hendriks 2009; Harrison \& Klein 2007) often do not benefit from it. Although Lauring and Selmer (20I2) affirm that few attempts have yet been made to link different types of diversity to knowledge sharing, some studies have been conducted on knowledge sharing in South Africa (Cloete 2007; Du Toit \& Steyn 20II; Finestone \& Snyman 2005; Kruger \& Johnson 2009; Ngulube 2005). However, there are limited examples from academe.

I. Luyanda Dube $(\mathrm{PhD})$ is a senior lecturer in the Department of Information Science, University of South Africa.

2. Patrick Ngulube (PhD) is a professor in the Department of Interdisciplinary Research of the College of Graduate Studies, University of South Africa 
Table I Profile of academics in the Department of Information Science, University of South Africa (UNISA)

\begin{tabular}{llll}
\hline Level & Number & Race & Nationality \\
\hline Junior Lecturer & $\mathrm{I}$ & White & South African \\
Junior Lecturer & 4 & Black & South African \\
Lecturer & $\mathrm{I}$ & Black & Non-South African \\
Lecturer & 3 & Black & South African \\
Lecturer & 5 & White & South African \\
Senior Lecturer & $\mathrm{I}$ & Black & South African \\
Associate Professor & $\mathrm{I}$ & Black & Non-South African \\
Professor & $\mathrm{I}$ & White & South African \\
\hline
\end{tabular}

Therefore this article seeks to give an overall view on how knowledge is shared across intergenerational, cultural and interracial layers in the Department of Information Science at Unisa. Specifically, the article focuses on tacit knowledge which exists with or within individuals, in order to examine how different types of diversity traits influence the process of sharing knowledge between individuals.

\section{Statement of the problem}

Knowledge sharing can give an organisation a competitive advantage. The people engaged in the process of knowledge sharing may enhance their performance through exploiting their collective intellectual capital. Little is known about knowledge sharing in culturally diverse academic environments in the context of South Africa. This investigation was guided by the following four research questions:

I. To what extent do knowledge sharing strategies exist in the Department of Information Science?

2. To what extent do academics share knowledge across race, age, gender and nationality in the Department?

3. Does the Department have a knowledge sharing culture?

4. Does the Department harness some of the knowledge sharing critical success factors such as cultivating trust, enhancing communication, exploiting the capabilities of information and communication technologies and rewarding individuals?

\section{Knowledge sharing: an overview}

Knowledge sharing is seen as a dual process, a social interaction activity which involves someone providing guidance, sharing ideas and giving advice to someone who is learning-by-observation, listening and asking (Gurteen 1999; Riege 2005; Janus-Hiekkarranta 2009). The interaction is mutually beneficial. The benefits of knowledge sharing abound and they outweigh the problems of not sharing it (Kamal, Manjit \& Gurvinder 2007). They include permitting personal development, career progression and improved performance (Jarvenpaa \& Staples 200I), which consequently result in positive spin-offs. Bartol and Srivastava (2002) and Butler el al., (2004) indicate that there is a growing realisation that knowledge sharing is critical to knowledge creation, organisational learning and performance achievement. Similarly, Bouthillier and Shearer (2002), Cabrera and Cabrera (2002), Gafoor and Cloete (2010) and Griffiths (1998) hold that without knowledge sharing, people in organisations tend to remain fixed in silos, poorly knitted together, prone to duplication of work and repetition of mistakes, wastage of resources, forgetful of good ideas, and without the harnessing of strengths All of this is time-consuming, costly and can lead to ineffectiveness and inefficiencies.

However, despite the benefits of knowledge sharing, it is acknowledged in the literature that even under the best circumstances knowledge sharing within an organisation is a multifaceted, complex process (Hendricks 1996; Lessard \& Zaheer 1996; in Ipe 2003). It needs to be harnessed and understood. Similarly, knowledge sharing processes are highly susceptible to negative or positive social, political, intergenerational, interracial, cultural and other realities (Cabrera \& Cabrera 2002). Realistically it is such realities that entrench heterogeneous traits that usually result in different values and attitudes (Botha 2003; Cloete 2007; Du Toit \& Steyn 20II; Kruger \& Johnson 2009). The South African case is rather unique because apartheid policies institutionalised heterogeneity and divisions. Given that knowledge is ingrained in people and social structures and thus context-bound, inherent disparities (Kamal, Manjit \& Gurvinder 2007) build up or mould distinct knowledge sharing behaviours and practices. Such behaviours emerge at different levels from an individual to an organisational level (Janus-Hiekkarranta 2009; Kamal, Manjit \& Gurvinder 2007), and vice versa.

For instance, Singh (200I) highlights that in South Africa, knowledge management sharing evolved along different trajectories. On the one hand, there are those who seek to preserve apartheid and on the other, there are those who 
seek to overcome it and replace it with a democratic alternative. These trajectories not only permeate the political and social landscape but also lead to the evolution of diversity and heterogeneity within organisations which may create a lack of trust and scepticism and subsequently politicking and hostility towards knowledge sharing (Kamal, Manjit \& Gurvinder 2007). That not only compromises knowledge flow but makes the sharing process even more challenging (Cloete 2007; Ford \& Chan 2003; Finestone \& Snyman 2005; Kruger \& Johnson 2009; Du Toit \& Steyn 20I I). Edge (2005) in Gafoor and Cloete $(2010)$ cautions that the dynamics emanating from heterogeneity and multiculturalism usually lead to the development of a culture of hoarding knowledge and resistance.

It has come out strongly in the literature that sharing knowledge is unnatural (Davenport 1997 in Bock \& Kim 2009). The argument is that in a strict sense, knowledge cannot be shared as it is not like a commodity that can be passed around freely and it is tied to a knowing subject (Hendricks 1999). Thus one can deduce that hoarding knowledge and retaining suspicions on the part of both the communicator (knowledge owner) and the receiver (knowledge re-constructor) (Hendricks 1999), is a natural tendency that may be worsened by heterogeneous traits.

\section{Methodology}

This is an exploratory piece of research which seeks to explore the extent to which knowledge is shared in an academic environment from an interpretivist perspective. A qualitative approach was considered appropriate for this study because it focuses on observing events from the perspectives of those who are involved and is aimed at understanding the attitude, behaviour and opinions of those individuals (Powell \& Connaway 2004). Mohsam and Van Brakel (20II) also used a qualitative approach to investigate knowledge sharing in small businesses in South Africa. As with Ely (1991:4), the aim was to have "those who are studied to speak for themselves, to provide their perspectives in words and other actions". A basic interpretive qualitative research design was used for this study (see Welman \& Kruger 200I; Merriam 2002). The results of a study that employs a basic interpretive design are interpretative and descriptive as is this case with this research. Data was collected through interviews and document analysis. As Merriam (2002:7) advises, the data were "inductively analyzed to identify the recurring patterns or common themes that cut across the data. A rich descriptive account of the findings is presented and discussed, using references to the literature that framed the study in the first place".

\section{Findings and discussions}

This section presents the findings of the investigation based on the literature that informed the study and the interviews and observations made by the researchers.

4.1 To what extent do knowledge sharing strategies exist in the Department of Information Science?

In view of the foregoing arguments, there are fundamentals that need to be carefully considered by the organisation to ensure that there are strategies in place to mitigate the impact of the negative influences on the process of knowledge sharing within the organisation. An understanding of knowledge sharing procedures and processes is critical to lessening scepticism and developing openness which may ultimately create trust among employees. Importantly, the strategy should take into account individual factors (given that members of different cultures have different kinds of frames of reference) and organisational factors, so that it may create an environment which is sensitive to diversity (Cloete 2007; Ford \& Chan 2003; Kruger \& Johnson 2009). Equally important, acknowledge sharing strategy will clarify structural or procedural factors, division of roles and responsibilities among employees and enhance cross-functional and crossdepartmental collaboration (Cabrera \& Cabrera 2002). Interviews with staff members revealed the following:

- There was a lack of institutional policies to guide knowledge sharing practice. Hence knowledge sharing was minimal and was not fully understood or institutionalised.

- There were limited strategies for recognising or rewarding knowledge sharing initiatives.

- Institutional policies did not fully enhance knowledge sharing because individual rather than group performance was rewarded and revered.

One respondent said, "The importance of knowledge sharing is unknown in this Department, and one wonders why people should get from others that which they learnt for themselves overtime. Why should it be made easy for new entrants?" Despite the negative views expressed by most of the respondents, some pointed out that even though there were no institutionalised strategies for sharing knowledge, there were moves to formulate and implement knowledge sharing plans. They mentioned that there were mentoring programmes for categories of staff, such as those who had recently joined the Department, young academics and inexperienced supervisors. As one interviewee put it:

You are saying most of the information you have gathered points to a lack of mentoring strategies in the Department. However, I differ on that. How would you classify activities involving an inexperienced supervisor being paired with a senior and successful supervisor to oversee masters and doctoral research projects? Is that not some kind of mentorship and indeed knowledge sharing? Maybe what we need to do is to formalise the 
need for the pairing of supervisors. I think what is lacking is a formal policy, but many circles in the Department and the University are advocating for this supervision model.

Informants did not have a shared understanding of knowledge sharing activities in the Department. One of the fundamentals of implementing knowledge sharing is to have a clear and all-encompassing knowledge sharing strategy/ policy to demystify the knowledge sharing process and combat classic phobias and clarify inherent procedures (Schultze \& Boland 2000). Combating phobias is critical to ensuring that related knowledge sharing activities and procedures are understood and embraced by contributors, as well as recipients of knowledge (Butler et al., 2004).

4.2 Sharing of knowledge across race, age, gender and nationality by academics

South Africa has been referred to as the "rainbow nation", a title which epitomises the country's racial, cultural, ethnic and national diversity. However, the South African situation is complicated by the depth and breadth of diversity in terms race, skills, culture and languages and also by a sensitivity which breeds silence around culture and related issues (Du Toit \& Steyn 201I; Finestone \& Snyman 2005). This cultural blindness or silence may create misunderstandings, misconceptions and trepidation (Ocholla 2002). Differences in demographic characteristics, and in particular, in clearly visible traits (age, gender and race) create fault lines that could function as barriers to interaction (Lau \& Murnighan I998), and decrease social attachment and interaction because of inherent dissimilarities (Lauring \& Selmer 20I2). However, the majority of the informants revealed that they did not have any problems with sharing their knowledge across race, age and gender lines. They argued that they were not motivated to share knowledge on the basis of race, gender and nationality at all. On the contrary one informant said:

People appear to have no problems with sharing knowledge across the various divides of the rainbow nation, but questions arise on the genuineness of the exercise. I am of the view that sharing is superficial. When it comes to in-depth knowledge there are cliques. In meetings, for example, people do not contribute. Instead of asking questions people prefer to have mini- meetings, that are clearly defined by racial and gender boundaries, after most Departmental meetings. At superficial level I would say yes, but at another level you choose the people with whom you want to share. In the meetings everybody says everything is fine, but you would be surprised to discover that certain individuals then go to the office of the Chair of Department to comment negatively about other people's work, conduct and abilities.

It turned out that the concerns of this informant were shared by a number of interviewees. With hindsight some of the apparent glaring contradictions that emerged from the analysis of data would have been resolved by using a different data collection technique. Perhaps focus group interviews may have worked better than individual face-to-face interviews. One informant argued that age was an important factor in sharing knowledge because from his cultural perspective age tends to create unequal relations. The argument was that elders are not likely to value the knowledge of young novices, thus making the playing field uneven and unconducive to knowledge sharing.

South Africa's multiculturalism is not unique. Cultures within countries are not homogenous and even less so in organisations (McDermontt \& O'Dell 200I). Furthermore, within organisations subcultures are characterised by a distinct set of values, norms and practices, resulting in some members valuing knowledge differently to other groups in the organisation (Petland 1995 in Ipe 2003). Is cultural diversity bad or does it have some positive attributes? Trefry (2006) infers that cultural diversity has some positive aspects, such as diluting uniformity in mental models as diverse people with different frames of reference are likely to interrogate existing paradigms or underlying assumptions and beliefs in their evaluation of the organisation. Further, multiculturalism allows one to access a broader pool of distinct knowledge, perspectives and insights than is available in a homogeneous group (Lauring \& Selmer 201 I; Ocholla 2002; White 1999). Indeed, cultural diversity is a not only a collective strength, but also brings about a plurality of knowledge, wisdom and energy, which enables people to express their opinions, contrast their frames of reference and recognise that there are indeed many different ways to achieve goals (Du Toit \& Steyn 20II; Johannesburg Declaration on Sustainable Development 2002).

The results from the interviews cast doubt over the perceived benefits of multiculturalism. Instead they illuminated the ingrained influence of behaviours that were modelled on political and other social persuasions. The plurality of knowledge that tends to benefit organisations did not seem to benefit the multicultural Department of Information Science at all. It is evident that multiculturalism did not act as a catalyst to sharing knowledge informed by various cultural frameworks. Sharing of knowledge across cultures was very rare as many informants revealed. Staff members tended to share knowledge within their racial groups and with those elements that championed values and behaviours similar to theirs. One informant summed up the situation prevailing in the Department in the following words:

SA Jnl Libs \& Info Sci 2012, 78(I) 
You must bear in mind that knowledge sharing is voluntary. How can one be expected to share quality critical and valuable knowledge with the others dissimilar to one against a current background of scepticism and antagonism.

The following response from one of the interviews is revealing:

With the entry of non-whites who, although they are qualified lack tacit knowledge, the know-how and procedural knowledge that those who have been in the system for a long time have acquired, there seems to be a general attitude of "let's see how you execute your duties?" There is subtle competition across racial lines. If you are white the feeling is that why would one want to share knowledge with people to whom the University gives preferential treatment in terms of current labour laws (for instance, the previously so-called disadvantaged individual will be considered for promotion ahead of a white counterpart).

4.3 Culture of sharing knowledge

Several studies have shown that having the best knowledge sharing strategy in place is not enough. It must be founded on a solid basis and supported by all the critical enablers that will mitigate impediments to knowledge sharing such as inadequate organisational structures and a lack of sharing-friendly organisational cultures (Davenport \& Prusak 1998; Tissen et al., 1998 in Hendricks 1998).

McDermott and O'Dell (200I) define organisational culture as the shared basic assumptions that an organization learns over time to create a unique culture that reflects the organisation's identity both visible and invisible. The visible dimension of culture is reflected in its espoused values, philosophy and mission while the invisible dimension lies in the unspoken set of values that guide employees' actions and perceptions in the organisation (McDermott \& O'Dell, 200I).

All the informants vehemently denied the existence of a knowledge sharing culture in the Department. They cited a lack of collaborative research projects in the Department and limited co-authorship of research articles in scientific journals as evidence of this absence. The majority of the informants confessed that they had never co-authored an article with a colleague in the Department. They also cited the absence of schemes to reward collaborative activities as evidence of a lack of a system to promote a knowledge sharing culture. The lack of collaboration between colleagues was confirmed by a content analysis of the Department's research outputs published in accredited journals from 2000 to 2012. There were only seven instances of co-authored articles during that period. Joint presentations at conferences were also minimal and they rarely crossed racial and gender boundaries. The interviews also revealed that knowledge hoarding was very rife in the Department.

Clearly, the Department's culture has to become more conducive to knowledge sharing processes. There is need to drive, support, popularise and institutionalise a knowledge sharing ethos. Smith and McKeen (2002) and Dean (2008) suggest that the organisational culture should evolve from one of knowledge hoarding to one that actively encourages and facilitates knowledge sharing and discourages industrial age thinking and behaviours. However, Dean (2008) points out that knowledge sharing cannot be forced on people; it can only be negotiated with people (Spalek 2007). A knowledge management strategy can be easily developed where there is a culture of sharing (Ngulube 2005).

4.4 Knowledge sharing: critical success factors

Organisational culture as the overarching framework has to be enabling to harness other knowledge sharing critical success factors (Ismail \& Al-Marzooqi 2007). The critical success factors as adapted from Ismail and Al-Marzooqi (2007) are trust, communication, information communication technologies and rewarding people for sharing knowledge.

\subsubsection{Trust}

Processes of sharing, distributing and utilising knowledge largely depend on trust (Ngulube 2005). The cost of low trust is detrimental because personnel involvement, commitment, and organisational success are compromised unlike in the case of high trust environments (Serrat 2009; Dean 2008). It stands to reason that organisations can reap benefits from strengthening trust as this leads to openness, honesty and shared goals and outputs. In particular, interpersonal trust is an antecedent to knowledge sharing as it is the magic ingredient that creates strong ties between the knowledge source and the knowledge seeker (Levin et al., 2002). The fact that there are various definitions of trust makes the concept all the more elusive (Levin et al., 2002). However, trust seems to be history-dependent phenomenon in which the willingness to trust another party is affected by one's history with that party and personality (Serrat 2009).

The apartheid legacy with its emphasis on creating divisions and heterogeneity based on, amongst other things, ethnic, cultural and racial physiognomies led to different value systems that were injurious to trust. Interestingly, the creation and deconstruction of apartheid legacy, through for example, affirmative action, has proven to be detrimental to trust and knowledge sharing (Du Toit \& Steyn 20I I; Finestone \& Snyman 2005; Kruger \& Johnson 2009). If the ingrained ranges are amplified, it begs the question whether the development, extension and restoration of trust among different orientations is possible. It was evident from the research that the lack of trust amongst colleagues, especially across racial lines, 
created a "them" and "us" environment and mentality. As can be deduced from a study conducted by Finestone and Snyman (2005), the issue of a lack of trust among different groupings is critical more so because it is a sensitive issue that attracts silence or antagonism which again has a detrimental effect on knowledge sharing. The results from the interviews conducted with members of staff in the Department seemed to suggest that many of them doubted whether they were honest with each other and they believed that an atmosphere of openness did not prevail in the Department.

The development of trust among different groupings may be difficult because it involves changing people's behaviours, tendencies and bringing them together at a level where they are comfortable to share. But all is not lost. Finestone and Snyman (2005) suggest that trust-building relationships may be based on continual support and nurturing. Additionally, progressive empowerment initiatives at personal and professional level are capable of heightening the capacity to trust and may improve what people perceive to be theintentions within different groups, thus improving levels of trust(Cabrera \& Cabrera 2002; Du Toit \& Steyn 20I I; Kruger \& Johnson 2009).

\subsubsection{Communication within the organisation}

Communication between staff members is critical in knowledge sharing given that knowledge is bound to people and social structures and expressed through language. Language barriers may influence knowledge sharing because people will be reluctant to share if they were not comfortable with the language of business (Alavi, Leidner \& Kayworth 2006; Cabrera \& Cabrera 2002; Finestone \& Snyman 2005; Lauring \& Selmer 201I). In South Africa, for instance, the Constitution recognises and guarantees equal status to eleven languages. One of these languages, English, is generally understood to be the language of business, politics and the media, and the country's lingua franca. However, regardless of the widespread understanding of the English language, Finestone and Snyman (2005), Kruger and Johnson (2009) and Du Toit and Steyn (20II) have noted that not everyone is comfortable using English as a lingua franca. This affects interactions across the cultural spectrum. The interview results revealed that the discrepancy in linguistic competencies was a barrier to knowledge sharing and interactions at an individual level. For instance, there have been cases where some staff members were ridiculed for linguistic incapacity. Although this is often done in a subtle way, it made some colleagues uncomfortable to communicate with others using the English language.

However, communication entails more than just language. It also includes strategies or modes of transferring the knowledge. It is in this regard that Smith and McKeen (2002) advocate the building of islands of sharing (i.e. communities of practice) and then build bridges between those islands. They further explain that knowledge sharing efforts are likely to succeed if they are incubated in small niche areas of the organisation before going widespread. This preceding notion is similar to that expounded in the theory of diffusion of innovations by Rogers (2003), which dictates that an innovation is an idea, practice or an object that is perceived new by an individual or a unit. The new idea will then be communicated along with its benefits and subsequently adopted. However, different individuals or groups will have different adoption speeds. Some are inventors, some early adopters and others are laggards or late adopters (Rogers 2003). This model may be used in the Department where formal communities of practice were nonexistent, with some few adjustments. Some communities of practice may be established among a few individuals and then expanded to the whole Department. The weekly meetings that the Department holds may be utilised to build social capital and cultivate the communities of practice. This makes sense, especially in culturally diverse environments where there may be a lot of mistrust and scepticism.

\subsubsection{Information communication technologies}

Considering that the fact that we are in the knowledge economy, Bartol and Srivastava (2002) affirm that it is undeniable that knowledge sharing and exchange relies heavily on technology-based mechanisms for knowledge creation, capture, management, sharing and storage. However, Cabrera and Cabrera (2002); Finestone and Snyman (2005) and JanusHiekkarranta (2009) caution that it is important to realise that technology is just a tool to enhance knowledge management practices. Therefore it should be appropriate and user friendly to ensure that it is utilised effectively and efficiently. Additionally, it is equally important to realise that although technology offers invaluable mechanisms for knowledge sharing there are challenges and pitfalls that may hinder its effective use. These include but are not limited to the following: information overload, bandwidth problems, lack of appropriate skills, changes in technology, maintenance and sustainability (Cabrera \& Cabrera 2002).

The respondents revealed that there were a variety of information and communication technologies that were at their disposal. They mainly used them to support the students as opposed to using them for knowledge sharing. The Department had a presence on the Facebook social networking site, but the site was rarely used to share knowledge as it was mainly for posting events in the Department. Some respondents were of the view that these information and communication technologies should be used to promote knowledge sharing. The assumption was that staff members in the Department were information specialists and would not find it difficult to use information, communication 
technologies and associated collaborative tools such as teleconferencing, YouTube, blogs and podcasts to share knowledge.

\subsubsection{Rewarding people for sharing knowledge}

What is the motivation for people to share knowledge? The underlying motivation for exchanging knowledge is fundamentally different, depending on the field, as indicated in studies conducted in different disciplines such as psychology, communication science, sociology and information science, to mention just a few. According to Wasko and Faraj (2000), the motivation to exchange knowledge is affected by whether the decision to share is viewed primarily as economic and motivated by self-interest, or non-economic and motivated by community interest and moral obligation. To take this argument further, there is an assumption that people have a tendency to have preferences when it comes to with whom they share (Lauring \& Selmer 2012). Having commonality, which is referred to as "homophily" in sociology seems to provide a motivation to share as "likeness begets liking". This article is partially premised on the assumption that similarity and dissimilarity between organisational members may provide the basis for informal connection and disconnection.

According to Syed-lkhsan and Rowland (2004), employees need a strong motivator, be it extrinsic or intrinsic, in order to share knowledge. Further, Makela, Kalla \& Piekkari (2007) affirm that it would be unrealistic to assume that all employees are willing to offer knowledge without considering what may be gained or lost as a result of this action. The idea of "what is in for me" is based on the social exchange theory which is predicated on the conviction that people are likely to help each other when there is a positive cost-benefit analysis in which the benefits are perceived to be greater than the costs (Cook \& Rice 2006). This was confirmed by one respondent who said:

The importance and value of knowledge sharing is unknown at Unisa. Why should people get from others that which they learnt for themselves over time: why should it be made easy for new entrants? Why does Unisa not give meaningful incentives to experienced people who waste their time sharing knowledge with new entrants and novices?

Some respondents identified with the reasons for not sharing knowledge articulated by Bartol and Srivastava (2002) thus:

I. fear of losing superiority based on ownership of that knowledge;

2. perception of not being adequately recognised and rewarded for a knowledge sharing action;

3. lack of time and resources to share knowledge; and

4. lack of trust associated with inferiority and superiority complexes that are usually prevalent as result of cultural and racial ranges

The fear of losing competitive advantage is more applicable in situations where incentives are aligned with extraordinary performance identified through performance appraisal systems, which imply that sharing one's skills with others may harm one's capacity to outperform the rest (Bartol \& Srivastava 2002; Bouthillier \& Shearer 2002). The reward system at Unisa tends to be biased towards individual performance as opposed to collective efforts. The interviews confirmed that the reward system as it stands promotes individualism rather than collaborative endeavours. In the words of one of the respondents:

Unisa does not value collaborative efforts in research. For instance, the Chancellor's Prize for Excellence in Research is only given to individuals. I have never heard of any group of researchers who received the award. When you go for promotion interviews you get a sense that that co-authorship of journal articles is frowned upon. Individual contributions are highly regarded as opposed to co-authored pieces. I am talking from experience and I am not fabricating anything here. Check for yourselves.

Some informants corroborated this stance. We did not find documentary evidence that could shed more light on this point.

Informants felt the reward system promoted the competition syndrome rather than cooperation. Spalek (2007) maintains that the downside of the knowledge economy is that it causes the workplace to be increasingly competitive. Smith and McKeen (2002) refer to a persistent industrial-culture belief that knowledge is power, money and competitive advantage. Trefry (2006) highlights the fact that the competition syndrome is ingrained in the company's frame of reference and dictates whether employees should take a cooperative or a competitive stance towards fellow employees. Similarly, Bartol and Srivastava (2002) argue that if in an organisation extraordinary performance determines higher ranking, status and compensation this might impact negatively on the sharing of knowledge because it will erode individual competitive advantage or the capacity to outperform the rest. In the South African multi-cultural context, many companies still function according to Eurocentric capitalistic principles and they promote self-interest, self-preservation 
and competitiveness (Finestone \& Snyman 2005). The Unisa reward system in general and in the Department in particular seems to reinforce these stereotypes.

To counter hoarding, organisations need to develop progressive policies and procedures that will not sanction nor recompense individual performance in favour of the collective efficiency.

\section{Conclusions}

In summary, the article assumes that there are variables that have to be carefully considered for knowledge sharing to flourish in diverse environments. The paper does not come up with absolute answers but highlights pertinent issues and encourages further research. The findings reveal that knowledge sharing in the Department is limited due to a number of systemic reasons, such as the absence of a knowledge sharing policy, the unsatisfactory reward system used by the Department, the spirit of the labour laws, a lack of trust and the underutilisation of information and communication technologies. Teamwork and what Habermas (1984) in Ngulube (2005) have called "communicative competence" are lacking. According to Habermas (1984) in Ngulube (2005), communicative competence refers to the ability of people to communicate objectively about factual matters, openly about ethical issues and sincerely about personal feelings. Any knowledge sharing strategy that the Department may want to institute should take into consideration some of the issues that this study raises. Similarly, the issue of lack of trust may be addressed by making sure that collaboration is based on clear rules which are understood, accepted and followed by everyone involved as advised by Janus-Hiekkarranta (2009). The Department should exploit the diversity it enjoys to its advantage. Diversity introduces different perspectives which should be nurtured to enhance the competitive advantage of the Department.

\section{References}

Alavi, M., Leidner, D. \& Kayworth, T. 2006. The role of culture in knowledge management: a case study of two global firms. International Journal of e-Collaboration, 2(I): I7-40.

Bartol, K.M. \& Srivastava, A. 2002. Encouraging knowledge sharing: the role of organizational reward systems. Journal of Leadership and Organisational Studies, 9(I):64-76.

Bock, G.W. \& Kim, Y-G. 2002. Breaking the myths of rewards: an exploratory study of attitudes about knowledge sharing. Information Resource Management Journal, I5(2): I4-2I.

Boone, C. \& Hendricks, W. 2009. Top management team diversity and firm performance: moderators of functional-background and locus-of-control diversity. Management Sciences, 55(2): I65-180.

Botha, D. 2003. An integrated framework for knowledge management based on the characteristics of the western, eastern and African national cultures. Innovation, 27: 13-20.

Bouthillier, F. \& Shearer, K. 2002. Understanding knowledge management and information management: the need for an empirical perspective. Information Research, 8(I). [Online]. http://informationr.net/ir/8-Ipaper/4I.html. Accessed 02 March 2010.

Butler, T., Feller, J., Poppe, A. \& Barry, P. 2004. Promoting knowledge sharing in government and non- government organizations using open source software: the pKADS story. Electronic Journal of e-Government, 2(2): 8I-94.

Cabrera, A. \& Cabrera E.F. 2002. Knowledge sharing dilemnas. Organisational Studies, 23 (5):678-7I0.

Cloete, F. 2007. Knowledge management and trust in government: lessons from South Africa. 7th Global Forum on Reinventing Government, 26-29 June, Vienna, Australia. [Online]. http://unpanI.un.org/intradoc/groups/public/documents/unpan/ unpan025898.pdf. Accessed 30 March 2012.

Cook, K.S. \& Rice, E. 2006. Handbook of social psychology: social exchange theory. Kluwer Academic/Plenum Publishers: New York.

Davenport, T.H. \& Prusak, L. 1998. Working knowledge: how organizations manage what they know. Boston, MA: Harvard Business School Press.

Dean, G. 2008. Organisational knowledge: capturing its diversity and sharing its power. [Online]. http://www.em.gov.au/ Documents/ALIES\%202009\%20-\%20Geoff\%20Dean.pdf. Accessed 30 March 2012.

Du Toit, A. \& Steyn, P. 20II. Knowledge management as a strategic management tool at a South African enterprise. African Journal of Business Management, 5(I 3):5083-509 I.

Ely, M. 1991. Doing qualitative research: circles within circles. London: The Falmer Press.

Finestone, N. \& Snyman, R. 2005. Corporate South Africa: making multicultural knowledge sharing work. Journal of Knowledge Management, 9(3): I28-|4|.

Ford, D.P. \& Chan, Y.E. 2003. Knowledge sharing in a multi-cultural setting: a case study. Knowledge Management Research and Practice, I(I):II-27.

Gaffoor, S. \& Cloete, F. 2010. Knowledge management in local government: the case of Stellenbosch Municipality. South African Journal of Information Management, I2 (I). [Online]. http://www.sajim.co.za. Accessed 25 August 2010.

Griffiths, P. 1999. Knowledge and information management in the public sector. London: Ark Group Limited in association with Inside Knowledge.

Gurteen, D. 1999. Creating a knowledge sharing culture. Knowledge Management Magazine, 2(5). [Online]. http:// www.gurteen.com/gurteen/gurtee.nsf/id/ksculture. Accessed 2 March 2010.

Harrison, D.A. \& Klein, K.J. 2007. What's the different diversity constructs as separation, variety or disparity on organisations. Academy of Management Review, 32(4): I I 99- 1228.

SA JnI Libs \& Info Sci 2012, 78(I) 
Hendricks, P. 1999. Why share knowledge? The influence of ICT on the motivation for knowledge sharing. Knowledge and Process Management, 6 (2): 91-100.

Ipe, M. 2003. Knowledge sharing in organizations: a conceptual framework. Human Resource Development Review, 2(4): 337359.

Ismail, A.I., Al-Marzooqi, N.Y. \& Mohammed, Y.F. 2007.Organisational culture and knowledge sharing: critical success factors. Journal of Knowledge Management, I I (2):22-42.

Ismail, M.B. \& Yusof, Z.M. 2008. Knowledge sharing models: do they really fit public organizations? IEEE. [Online]. http:// ieeexplore.ieee.org. Accessed 30 March 2012.

Jain, P. 2009. Knowledge management in e-government. Journal of Knowledge Management Practice, I0(4). [Online]. http;// www.tlainc.com/articl203.htm. Accessed I3 May 2010.

Janus-Hiekkarranta, A. 2009. Developing a comprehensive knowledge management approach for ICT-based professional services companies: a case study. Masters Thesis, Technology management and Policy. Department of Business Technology. Helinski School of Economics. [Online]. http://hsepubl.lib.hse.fi/FI/ethesis/pdf//2/98/hse_ethesis_I2/98.pdf. Accessed I2 February 2012.

Jarvenpaa, S.L. \& Staples, D.S. 200I, Exploring perceptions of organizational ownership of information and expertise. Journal of Management Information Systems, I8(I): I5I-183.

Johannesburg Declaration for Sustainable Development. 2002. Report of the World Summit on Sustainable Development, Johannesburg: South Africa. [Online]. http://www.unctad.org/en/docs/aconfl99d20\&cl_en.pdf. Accessed I2 January 2012.

Kamal, K.J., Manjit, S.S. \& Gurvinder, K. S. 2007. Knowledge sharing among academic staff: a case study of Business School in Klang Valley, Malaysia. Research Papers. [Online]. http://www.ucsi.edu.my/cervie/ijasa/volume2/pdf/08A.pdf. Accessed I 2 June 2012.

Kruger, C.J. \& Johnson, R.D. 2009. Assessment of knowledge management growth: a South African perspective. Aslib Proceedings New Information Perspectives, 6I(6):542-564.

Lau, D.C. \& Murnighan, J.K. 1998. Demographic diversity and faultlines: the compositional dynamics of organizational groups. Academy of Management Review, 23(2): 325-340.

Lauring. J. \& Selmer, J. 20II. Multicultural organizations: common language, knowledge sharing and performance. Personnel Review, 40(3):324-343.

Lauring, J. \& Selmer, J. 2012. Knowledge sharing in diverse organisations. Human Resource Management Journal, 22(I):89-I05.

Levin, D.Z., Cross, R., Abrams, L.C. \& Lesser, E.L. 2002. Trust and knowledge sharing: a critical combination. IBM Institute for Knowledge-Based Organisations. [Online]. http://www- 935.ibm. Accessed 08 March 2012.

Lopus, L. 2010. Building trust in organisations. [Online]. http://blog.bcwinstitute.org/?p=I28. Accessed 8 March 2012.

Makela, C., Kalla, H.K. \& Piekkari, R. 2007. Interpersonal similarity as a driver of knowledge sharing within multinational corporations. International Business Review, I6(I): I-22.

McDermott, R. \& O’Dell, C., 200I. Overcoming cultural barriers to sharing knowledge. Journal of Knowledge Management, 5(I):76-85.

Merriam, S.B. 2002. Qualitative research in practice: examples for discussion and analysis. San Francisco: Jossey-Bass

Mohsam, F. \& Van Brakel, P.A. 20I I. Information and knowledge sharing trends of small and medium-sized enterprises in the Western Cape, South Africa. SA Journal of Information Management, I3(I), Art. \#462, I0 pages. [Online]. http://dx.doi.org/ 10.4102/sajim.v13il.462. Accessed 10 March 2012.

Ngulube, P. 2005. Improving the quality of research outputs in higher education through knowledge sharing and collaboration: A case study. Mousaion, 23 (I), 39-6I.

Ocholla, D.N. 2002. Diversity in the library and information workplace: a South African perspective. Library Management, 23(I/2): 59-67.

Powell, R. R. \& Connaway, L. S. 2004. Basic research methods for librarians. Connecticut: Libraries Unlimited.

Raja, S. \& Raja, K. 2008. The relationship of knowledge management practices, competencies and the organizational performance of government departments in Malaysia. World Academy of Science, Engineering and Technology, 48. [Online]. http://www.waset.org/journals/waset/v48/v48-9.pdf. Accessed 8 June 2012.

Rice, M.F. 2010. Diversity and public administration: theory, issues and perspectives. $2^{\text {nd }}$ edition. New York: M. E. Sharpe Inc.

Riege, A. 2005. Three-dozen knowledge sharing barriers managers must consider. Journal of Knowledge Management, 9(3): I835.

Rogers, E. 2003. Diffusion of innovations. $5^{\text {th }}$ edition. New York: Free Press.

Schultze, U. \& Boland, R.J. 2000. Knowledge management technology and the reproduction of knowledge work practices. Journal of Strategic Information Systems, 9: 193-212.

Serrat, O. 2009. Building trust in the workplace. Knowledge Solutions, 57. [Online]. http://www.adb.org/Documents/Information/ Knowledge-Solutions/Building-Trust-in-the-Workplace.pdf. Accessed 30 March 2012.

Singh, M. 200I. Knowledge management/knowledge sharing for social justice: the South African case. Knowledge, Research \& Innovation Co-operation, NN28 July 200I. [Online]. http://www.norrag.org. Accessed 8 March 2012.

Smith, H. A. \& McKeen, J.D. 2002. Instilling a knowledge sharing culture. Third European Conference on Organisational Knowledge, Learning Capabilities. Athens, Greece, March 2002. [Online]. http://business.queens.ca/centrres/monieson/ conference-papers.php. Accessed 8 March $201 \mathrm{I}$.

Spalek, P. 2007. Knowledge as a factor of production: how to make it effective with knowledge management methods. GTZ Bulletin, Knowledge Systems in Rural Areas, (16). [Online]. http://www.fao.org/fileadmin/user_upload/knowledge/docs/ GTZ bulletin 07.pdf. Accessed 10 October $201 \mathrm{I}$.

Trefry, M.G. 2006. A double-edged sword: organisational culture in multi-cultural organisations. International Journal of Management, 23(3):563-575.

SA Jnl Libs \& Info Sci 20I2, 78(I) 
Wasko, M.M. \& Faraj, S. 2000. "It is what one does": why people participate and help others in electronic communities of practice. The Journal of Strategic Information Systems, 9(2-3): I55- I 73.

Watad, M.M., Paterson, W. \& Perez-Alvarez, C. 2007. Knowledge sharing and cultural diversity and IT people: implications on knowledge management initiatives. [Online]. http://sbaer.uca.edu/research/allied pdf. Accessed I0 October $201 \mathrm{I}$.

Welman, J.C. \& Kruger, S.J. 200 I. Research methodology: for the business and administrative sciences. $2^{\text {nd }}$ ed. Cape Town: Oxford University Press Southern Africa.

White, R.D. 1999. Managing the diverse organisation: the imperative for a new multicultural paradigm. Public Administration \& Management: An Interactive Journal, 4(4):469-493. 